\title{
Recent Experiments in Aerospace and Design Engineering Education
}

\author{
William H. Mason, $*$ Harry Robertshaw ${ }^{\dagger}$ and Daniel J. Inman ${ }^{\ddagger}$ \\ Virginia Polytechnic Institute and State University \\ Blacksburg, VA 24061,
}

\begin{abstract}
This paper describes some recent capstone design experiences at Virginia Tech. Two new features of our design program are described. They both involve providing a hand-on experience, where the students build, test and fly concepts developed in the design class. In the first, seniors built a wind tunnel model and convinced juniors taking their lab class to test the model as part of that class in place of doing a traditional wind tunnel test. In the second, we formed a joint mechanical/aerospace engineering design team with the goal of designing, building and flying a morphing wing airplane. The seniors were notably more enthusiastic about these projects as compared to the traditional design projects. Surprising to us, the juniors were somewhat reluctant at first. They were concerned that performing a new concept test would result in a poor grade for them in their class. The combination of MEs and AEs was interesting. They each brought a different attitude to design. The MEs were more hand-on, "let's try it", whereas the AEs were more concerned with analysis. This combination was definitely better than the traditional single-major design teams normally used at Virginia Tech.
\end{abstract}

\section{Introduction}

This paper describes some project and hands-on approaches we've used recently with seniors in the capstone design sequence. The purpose has been to provide a balance between paper-study design emphasizing design methodology and approaches emphasizing construction of designs. Although building designs has been done in other programs, ${ }^{1,2,3}$ it is new to the senior Aerospace Engineering Design Program at Virginia Tech.

In the past we have presented several papers at education sessions of the AIAA. The first paper addressed the question of "Applied Aerodynamics Literacy,"4 and presented the results of a survey of the members of the AIAA Applied Aerodynamics TC. The next paper described case studies done in the Applied Computational Aerodynamics course that was being taught at that time..$^{5}$ That course is not taught today because it was a FORTRAN-based class, and students no longer learn FORTRAN. However, we still use case studies applying computational methods is other courses.

\footnotetext{
* Professor, Department of Aerospace and Ocean Engineering, Associate Fellow, AIAA, whmason@vt.edu, http://www.aoe.vt.edu/people/whmason.html

${ }^{\dagger}$ Professor, Department of Mechanical Engineering

${ }^{\ddagger}$ G.R. Goodson Professor and Director

Center for Intelligent Material Systems and Structures, Department of Mechanical Engineering, Fellow AIAA

Copyright (C) 2004 by William H. Mason. Published by the American Institute of Aeronautics and Astronautics, Inc., with permission.
}

Another aerodynamics education paper $^{6}$ contained two themes. First, William Devenport described a modern approach to aerodynamic education through the use of Java applets. ${ }^{7}$ These applets, available to everyone, are widely used at Virginia Tech and elsewhere, and indeed show up close to the top of a web search on "aerodynamics" on Google. The second part of the paper described how students learn, featuring a description of Perry's model of cognitive development. ${ }^{8}$ We remain convinced of the value of Perry's model as way to understand how we learn.

We have also written about design education. In particular, at Virginia Tech we have been including freshmen in "Senior" design for a number of years. We have also explored the use of design teams with members from several departments. This has been a good experience. ${ }^{9,10}$ Anyone interested in doing this would be advised to read these papers. Other papers on education-related issues have looked at software available for aircraft $\operatorname{design}{ }^{11}$, including aerodynamics, and the issues we found with students using these programs. We also discussed the educational issues associated with multidisciplinary design education. ${ }^{12}$ From our viewpoint it is hard to separate aerodynamics education from engineering design education. ${ }^{13,14}$

In 2002 we examined the issues associated with modern IT. ${ }^{15}$ This seemed to complete a cycle of educations papers, and it appeared we had nothing else to say. We were wrong. 
This paper describes two recent experiences that deserve to be shared with the broad aerospace community. The first innovation consisted of having students in the junior aerodynamics lab wind tunnel test a design that originated in the senior aircraft design class. The second innovation was the actual building and flying of a morphing wing airplane by a joint aerospace/mechanical engineering design team. Both of these new approaches took place during the 2002-2003 school year. Our willingness to try new approaches was at least in part based on the experience at MIT. ${ }^{16,17}$ We are continuing them this year (2003-2004).

\section{Summary of Our Previous Approach}

Usually, our aircraft design class consists of seniors during the first semester of the year-long course, followed by the addition of several freshmen to each design team during the second semester. Typically, most of our teams use the AIAA Undergraduate Team Aircraft Design RFP as the basis for their design project. The program starts with students doing individual assignments. These assignments include examining existing airplanes performing similar missions to the RFP, and developing concepts that address the RFP requirements. Then teams are formed and a preferred concept is selected at the end of the fall semester. The spring semester is a preliminary design of the concept selected at the end of the Fall semester.

\section{Postal Penguin}

One of the RFPs used in 2002-2203 was for the design of a UCAV for the US Navy, UCAV-N. ${ }^{18}$ One other interesting aspect of this project was that it was done in conjunction with an Ocean Engineering Design Team that was designing a UCAV-N dedicated carrier, which was of interest to the Navy.

As Team Eight-Ball was working on their design, they saw a video on PBS: "The Battle of the XPlanes." This was the story of the JSF competition. The video featured a design discussion at Boeing about the tail configuration selection. The team became excited about Ralph Pelikan's proposed configuration. This was for a novel configuration that used a so-called "two-post" concept to obtain pitch yaw and roll in place of the traditional "four post" arrangement. It did this using a skewed hinge line. Because the aerodynamics codes available to the team couldn't treat this case, they asked about wind tunnel testing it. In discussing the possibilities, it seemed like a good idea to have the juniors, who were going to be using the tunnel, test this tail in place of their normal lab experiment. The seniors built a tail-alone model, and provided it to the juniors to test. Figure 1 shows a schematic of the Pelikan tail concept, and Figure 2 shows the model the students built. The juniors obtained side force, lift and pitching moment data, which was used to satisfy their lab requirement, and used by the design team as part of their design development.

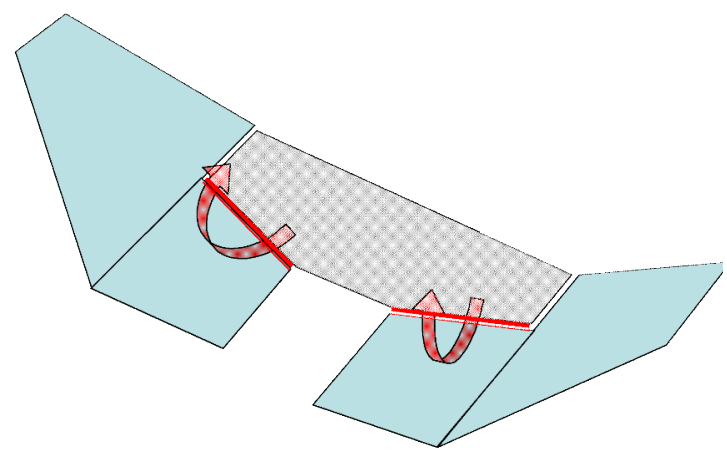

Figure 1. Pelikan tail concept, featuring the skewed hinge line.

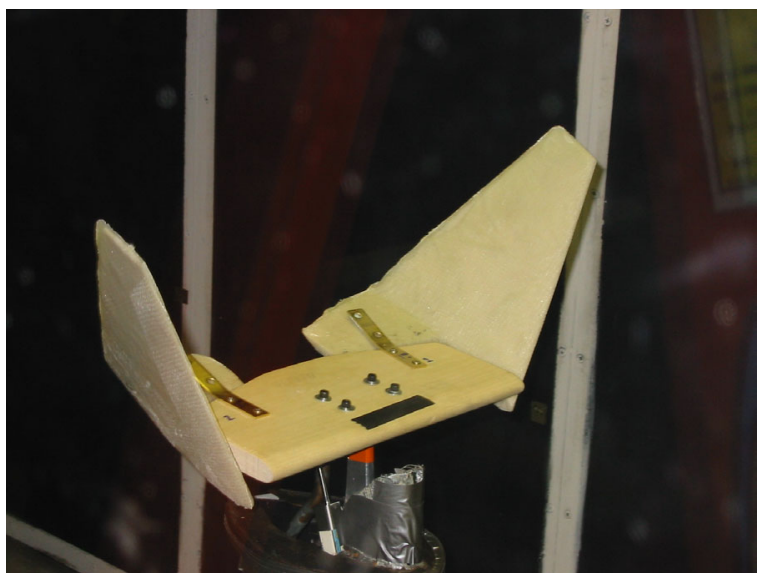

Figure 2. Pelikan tail as built by the design team, in the Virginia Tech Wind Tunnel

The result of this experience was positive. The seniors were enthusiastic. They got wind tunnel data for a novel tail concept, and were able to demonstrate that the concept would work on their design. They also gained an appreciation for the difficulty of designing and building the model to meet the hard deadline associated with the lab test date. Although initially skeptical, the juniors got to test a new concept and work closely with the seniors. From a departmental perspective this approach is helping us integrate our curriculum. The results from the test are available in the team design report, available on the web. ${ }^{19}$

We plan on continuing to have seniors select a concept and test it in the junior lab in the future. 


\section{Morphing Wing UAV}

Another innovation was introduced several years ago and proved to be successful. DARPA interest in morphing wing technology and support of a research project at Virginia Tech led to the idea of having seniors design, build, and fly morphing wing airplanes. The idea originated in the Center for Intelligent Material Systems and Structures in the Department of Mechanical Engineering. The ME design program emphasizes fabrication of concepts, so the goal from the outset was to build something. Because MEs don't have a strong background in some of the aspects of airplane design, it was natural to form a combined ME/AE design team. This is the third year of this program, and typically it involves about 6-8 MEs and 4-6 AEs. The class is conducted as a regular design section in both $\mathrm{ME}$ and $\mathrm{AE}$, with an instructor from each department participating.

In the first year the team examined three different means of changing wing camber smoothly for control: shape memory alloys, piezoelectric actuators, and servo-driven mechanisms. The designs were wind tunnel tested, but not flown. Figure 3 shows the design used in the first year. The model was a flying wing, based on the Zagi $400 \mathrm{X}$ model airplane kit It had an aspect ratio of 4.8, a taper ratio of 0.52 and a leading edge sweep of $30^{\circ}$.

The design effort was documented and is available..$^{20}$ Wind tunnel tests provided information on lift, drag, pitching moment and roll. Also, a vortex lattice program was written specifically to study the appropriate camber shape change distributions along the span to provide pitch and roll control, and also minimize drag over a range of lift coefficients. Although the airplanes weren't flown, the team did make their final design presentation at WPAFB.

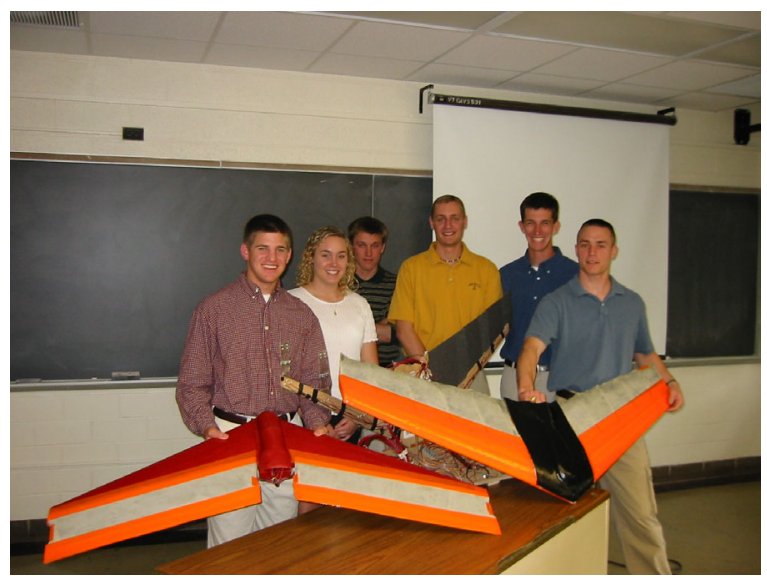

Figure 3. 2001-2002 morphing aircraft designs

In the second year of the project (2002-2003) emphasis was placed on actually building and flying a model. Instead of smoothly deflecting trailing edges as morphing, a more significant change was selected. Responding to DARPA interest in obtaining a $200 \%$ change in aspect ratio and a 50\% change in span, it was decided to produce a large change in wing area and span by developing a telescoping wing concept. Once again, a flying wing configuration was selected. Furthermore, it was decided to instrument the model and record control positions, flight speed, and roll rate among other quantities.

The development program was broken into several phases. A consideration was that few members of the team had any experience building or flying model airplanes. Thus, to increase the likelihood of success, a commercially available kit was selected as the baseline. After a study of candidates was made, the Delta Vortex model by Bruce Thorpe engineering was chosen. This was a 54-inch span, 1375 square inch wing area delta wing model of conventional balsa wood construction. It weighs about eight pounds. The model was selected because it provided the volume required to house the instrumentation, as well as the wing area required to support the weight of the instrumentation. Next, the model was built and flown without modification. It was flown first without instrumentation. This was done during the Fall semester. Because of poor weather this airplane in fact flew after the semester ended. The student interest was evident in that they continued to work on the project after the semester ended. The Delta Vortex continues to fly, and Figure 4 shows a takeoff of this airplane.

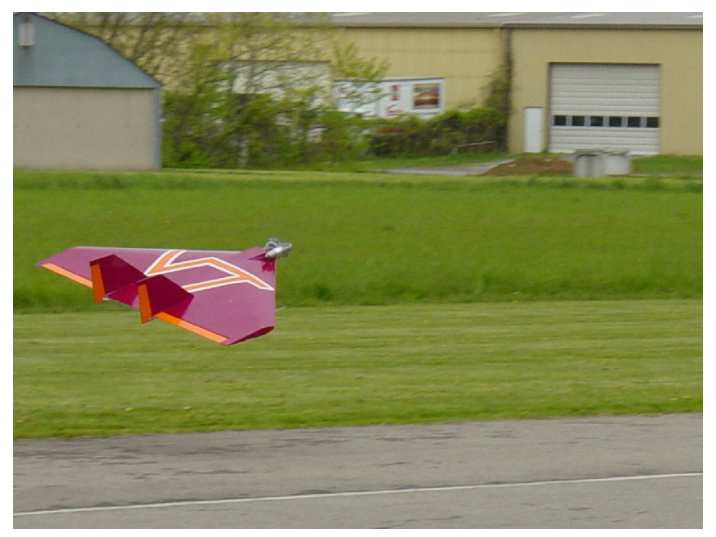

Figure 4. A takeoff of the delta vortex (note pitot tube on onboard wing station)

Next instrumentation was added and the plane flown again. The instrumentation was developed to measure airspeed, control surface/throttle positions. body rates and accelerations. The data was stored on a Crossbow AD2000 Data Logger. This instrument was developed for spacecraft applications and is supposed to be capable of withstanding several 
hundred $g$ 's. The device can accept eight channels of data, and has plenty of capacity for typical flights of 10-15 minutes. After the flight, the data was downloaded from the Data Logger to a laptop PC for analysis. Details of the model and instrumentation are available in the team's final design report. ${ }^{21}$

Next, the team bought another delta Vortex kit and modified it to incorporate a telescoping wing, designed to operate in flight. They called this model the BetaMax. It is shown under construction in Figure 5. First, the span of the original model was reduced. This amounted to "clipping the tip" to provide a enough chord to allow the telescoping wing to extend directly outward and have a reasonable chord. A consequence of this was that the area of the trailing edge elevons was reduced. The telescoping mechanism consisted of a rack and pinion gear mechanism, designed to make sure that both wing moved together.

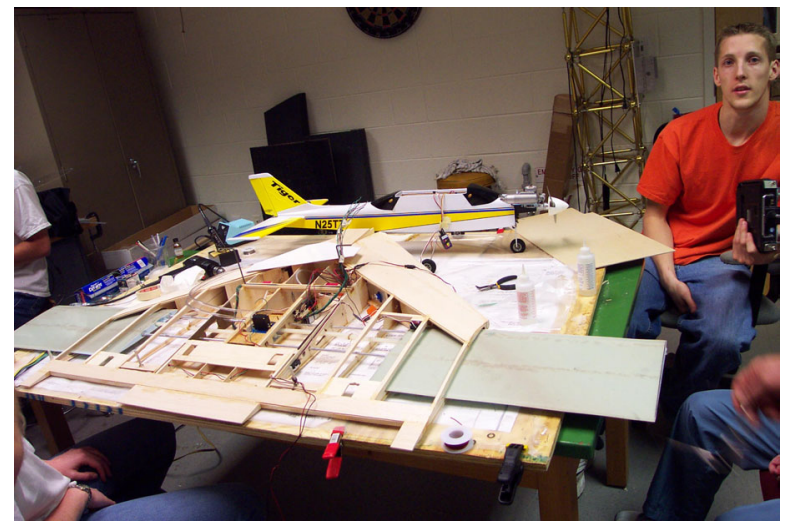

Figure 5. The morphing wing under construction at Virginia Tech

Figure 6 shows the Laptop hooked to the "data logger" which was carried onboard the airplane. The first attempt to fly this airplane failed. It was a good lesson for the team. Essentially, in the haste to fly the plane, several issues were ignored, and the analysis of the modifications was not done completely.

First, the weight increased significantly between the airplanes. As built at Virginia Tech, the Delta Vortex weight 10.2 pounds instead of the design weight of 8 pounds. The BetaMax weighed over 15 pounds. In addition, the center of gravity was located at the wrong place and the elevon area had been reduced by $25 \%$. Upon investigation, it was found possible to remove two pounds of weight from the plane, the center of gravity was moved and the elevons were extended to regain control surface area. At this point there was some figure pointing between the MEs and the Aes, and hopefully everybody got an appreciation for the importance of weight and center of gravity control. As eventually modified, the plane had a static margin of $11 \%$ with the wings extended, and $5.5 \%$ with the wings retracted.

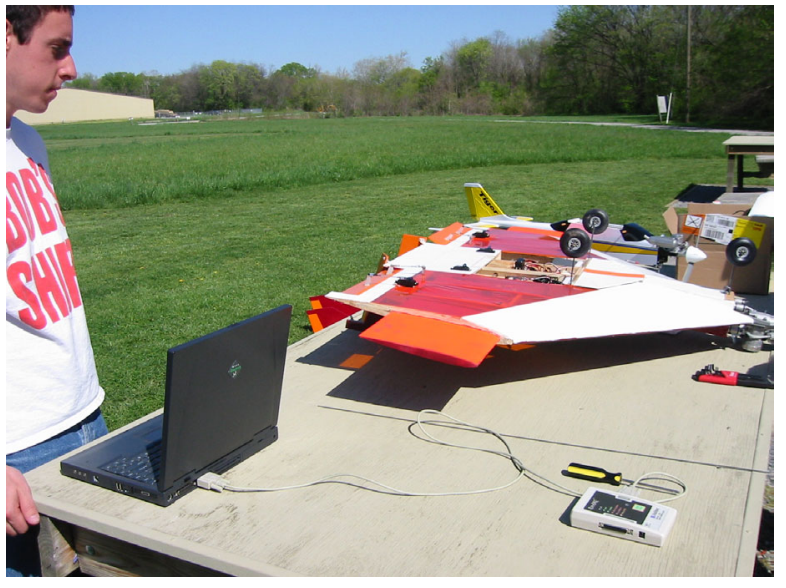

Figure 6. Laptop computer hooked to the data logger to download flight test data taken.

Finally, the morphing wing airplane had a successful flight. The BetaMax is shown in flight in Figure 7. Successful flights were made essentially at the end (and after) the Spring semester. Flights were delayed again due to the poor weather in Southwest Virginia.

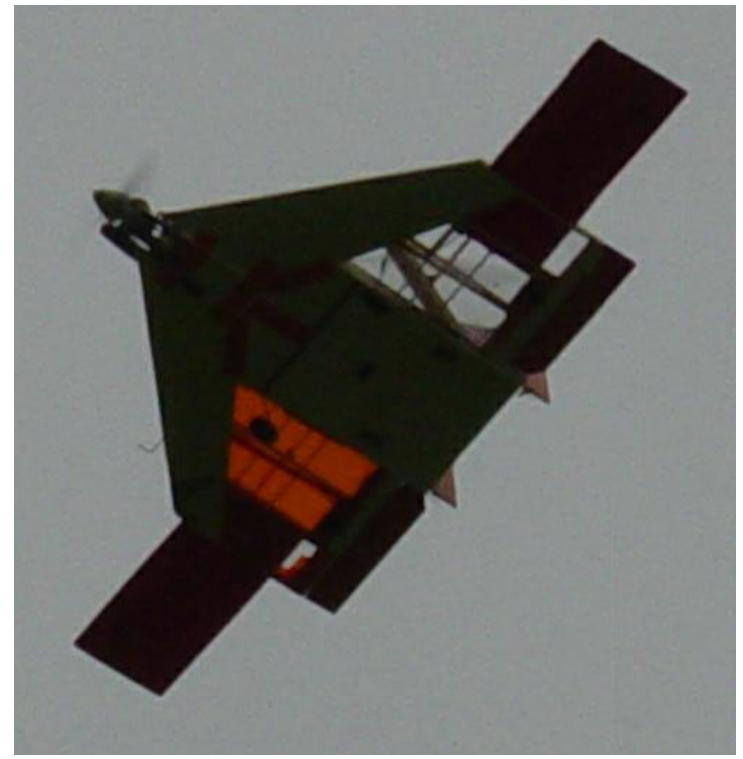

Figure 7. The BetaMax in flight, wings extended.

Key issues that arose and were solved included the weight of the BetaMax, vthe change of aerodynamic center as the wings morphed, and the reduction in the control power because the trailing edge control were reduced in size. These effects were very noticeable to the pilot.

Figure 8 shows our RC Plane fleet, which is still in tact after the year's flying. 


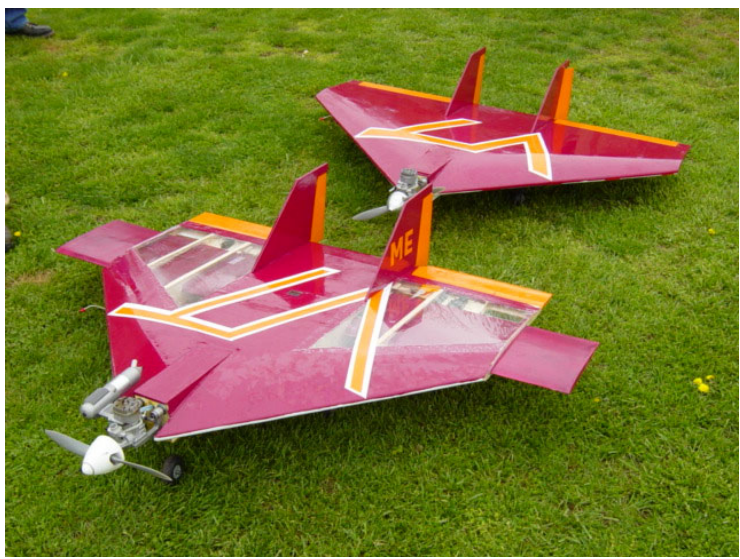

Figure 8. Our morphing wing airplane fleet.

In 2003-2004 the morphing project is continuing. This year the students were given two requirements. They met the fall requirement by extending the BetaMax capability to include roll control through asymmetric extension of the telescoping wings. They made a successful flight November 20, 2003. Figure 9 shows the team preparing for the flight, and Figure 10 shows the BetaMax in flight performing a roll using the asymmetrically extended telescoping wing mechanism.

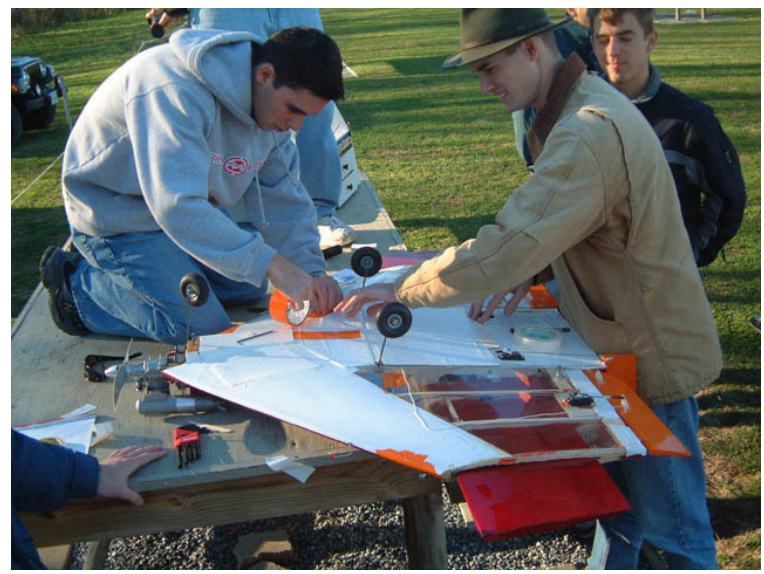

Figure 9. Senior design team prepare for flight.

The main issue that rose was interference between the two radio systems in use, one or the telescoping wings, and one for the rest of the controls. Data was taken on the flight measuring the response of the airplane to the asymmetric telescoping. They were able to obtain an extension rate of 12 inches/sec, and this proved to be enough to control the airplane.

The next goal is to build several new airplanes employing different morphing concepts. They will include variable wing incidence and variable camber. Flexible materials to be used for wing skins will be investigated. These models will be simpler, allowing for several different configurations to be flown.

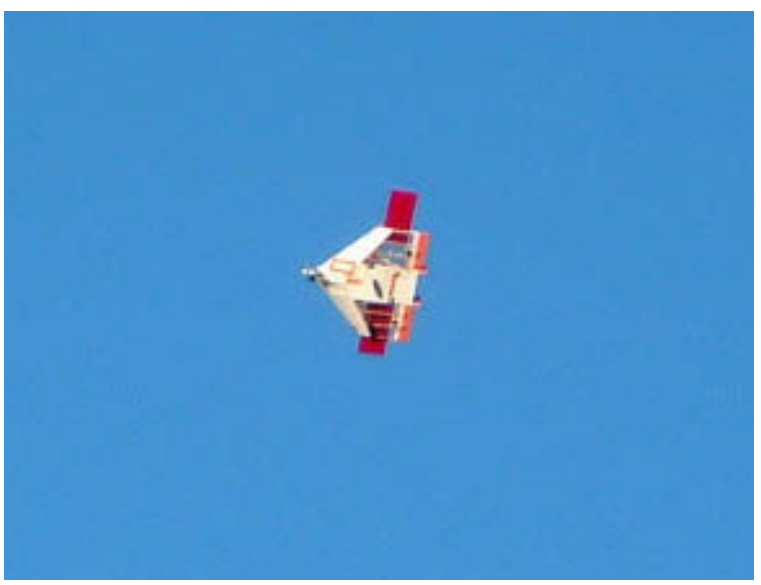

Figure 10. BetaMax in flight with asymmetric wing extension.

\section{Conclusions}

Our experience indicates that the hands-on approach to design generates more interest and leads to a better appreciation for the material than a typical paperstudy design course. Most, but not all, of the students worked harder than they would otherwise. Whereas paper studies could lead to debate with students about the quality of the work, the need to demonstrate the design in operation made evaluation simpler.

Experience with the morphing project showed the students the need to do analysis to be successful, and that this step can't be neglected. Failing to fly was dramatic evidence of this requirement, and showing the film to this year's students made the point, so that they did not repeat past mistakes.

The integration of students from different departments, even as seemingly similar as aerospace and mechanical engineering, results in the presence of different cultures. This enhanced the teamwork experience of the students, as well as providing a wider set of skills to do the design.

Finally, the students seemed to be impressed with the difficulty of meeting goals they had set for themselves within time and budget constraints.

Acknowledgements: Team Eight-Ball, that designed the Postal Penguin using the Pelikan tail, consisted of Justin Hayes, Ben Smith, Chuhui Pak, Greg Little, Alex Rich, David Andrews, and Nate Wright. The ME/AE Morphing Team consisted of: Matt McCarty, Laura Arrison, Kevin Birocco, Chuck Gayloard, Brandon Herndon, Katie Manion, Mike Metheny, Mike Cummins, Robert Foster, Nicolas Hanak, Tae Kwon, Marcus Topaske, Caroline Hutchison and Greg Wargo. Special thanks go to Kevin Birocco for assisting in the collection of the graphics, movies and data. Prof. William Devenport encouraged us to have seniors interact with the students taking the lab class 
he supervises. Finally, financial support for this project was provided by the Center for Intelligent Material Systems and Structures at Virginia Tech.

Note: Many of the references listed below, as well as the movies can be found at the author's web site: http://www.aoe.vt.edu/people/whmason.html

in particular, the senior design reports cited in this paper are available at:

http://www.aoe.vt.edu/ mason/Mason_f/SD1SrDesR pts.html

and this paper, with the movies available for download, is available at:

http://www.aoe.vt.edu/ mason/Mason_f/MRRpubs04 .html

\section{References}

${ }^{1}$ John Perkins, R. Mitcheltree, and R. Vess, "Aircraft Design Education at North Carolina State University," AIAA Paper 89-0649, $27^{\text {th }}$ Aerospace Sciences Meeting, Reno, NV, January, 1989.

${ }^{2}$ Stephen M. Batill, "Using Prototypes and Flight Validation in Teaching Aerospace Systems Design," 1991 SAE Aerospace Atlantic, Dayton, OH, April 22-26, 1991.

${ }^{3}$ Eli Livne, "Evolution of the Capstone Airplane Design Course at the University of Washington," AIAA Paper 99-0570, 37 ${ }^{\text {th }}$ AIAA Aerospace Sciences Meeting, Reno, NV, Jan. 11-14, 1999.

${ }^{4}$ W.H. Mason, “Applied Aerodynamics Literacy: What Is It Now? What Should It Be?" AIAA Paper 91-3313, AIAA $9^{\text {th }}$ Applied Aerodynamics Conference, Baltimore, MD, September 1991.

${ }^{5}$ W.H. Mason, “Applied Computational Aerodynamics Case Studies,” AIAA Paper 92-2661, $10^{\text {th }}$ AIAA Applied Aerodynamics Conference, Palo Alto, CA, June 1992.

${ }^{6}$ W.H. Mason, and W.J. Devenport, “Applied Aerodynamics Education: Developments and Opportunities," AIAA 16th Applied Aerodynamics Conference, Albuquerque, NM, AIAA Paper 98-2791, June 1998.

${ }^{7}$ http://www.engapplets.vt.edu/

${ }^{8}$ P.C. Wankat and F.S. Oreovicz, Teaching Engineering, McGraw-Hill, 1993, pp. 269-280.

${ }^{9}$ James F. Marchman, III and W.H. Mason, "Freshman/Senior Design Education," AIAA Paper 94-0857, January 1994.

${ }^{10}$ James F. Marchman, III, and W.H. Mason, "Freshman/Senior Design Education," International
Journal of Engineering Education, Vol. 13, No. 2, 1997, pp. 143-152.

${ }^{11}$ W.H. Mason, "Aircraft Design Course Computing Systems Experience and Software Review," ASEE Annual Conference, Sunday, June 25, 1995, Anaheim, CA

${ }^{12}$ W.H. Mason, Zafer Gürdal and R.T. Haftka, "Experience in Multidisciplinary Design Education," ASEE Annual Conference, Monday, June 26, 1995, Anaheim, CA

${ }^{13}$ W.H. Mason, "Aircraft Design at Virginia Tech: Experience in Developing an Integrated Program," AIAA Paper 95-3894, 1st AIAA Aircraft Engineering, Technology, and Operations Conference, Los Angeles, CA, Sept. 19-21, 1995

${ }^{14}$ Mark Gordon, Dan Schrage, Joel Greenstein, Jack Hebrank, Doug Hirt, Bill Mason, Tom Miller, and Jim Nau, "Early Design: Lessons and Strategies from SUCCEED”, Session 3225, 1996 ASEE Annual Conference and Exposition, Washington, DC, June 23-26, 1996.

${ }^{15}$ W. H. Mason, "Teaching Applied Aerodynamics in the IT Age", $20^{\text {th }}$ AIAA Applied Aerodynamics Conf., AIAA Paper 2002-2725, June 24-27, 2002, St. Louis, MO.

${ }^{16}$ P.W. Young, D. Miller, D.L. Darmofal, D.R. Brodeur. "Problem-based learning in aerospace engineering education," Proceedings of the 2002 American Society for Engineering Education Annual Conference \& Exposition, Montreal, June 2002.

${ }^{17}$ Darmofal, David, and Murman, Earll M., "Reengineering Aerodynamics Education," AIAA Paper 2001-0870, January 2001

${ }^{18}$ Scott L. Fowler, "UCAV-N RFP for the Virginia Tech 2002-2003 Aircraft Design Class," September 4, 2002.

${ }^{19}$ Team Eight-Ball, "Postal Penguin, An Unmanned Combat Air Vehicle for the Navy," Virginia Tech, May 1, 2003.

${ }^{20}$ Greg Eggleston, Caroline Hutchison, Chris Johnston, Brian Koch, Greg Wargo and Kelley Williams, "Morphing Aircraft Design Team Final Report," May 2, 2002, Virginia Tech.

${ }^{21}$ Laura Arrison, Kevin Birocco, Chuck Gaylord, Brandon Herndon, Katie Manion and Mike Metheny, "2002-2003 AE/ME Morphing wing Design," Virginia Tech, May 1, 2003. 